\title{
Relevance of Geographic I nformation Systems (GI S) and Remote Sensing (RS) to Environmental Education: A Panacea for Sustainable Development in Nigeria
}

\author{
Muhammad, Mansur Aliyu \\ Department of Geography \\ Shehu Shagari College of Education, Sokoto- Nigeria
}

\section{Doi:10.5901/ ajis.2013.v2n10p75}

\begin{abstract}
Human have demonstrated interaction with the environment through the quest for industrial development, increase in agricultural products, construction of roads, houses and social amenities, fishing for food, mining, excavation and other human activities, all of these have indeed led to a serious environmental problems, however on daily basis, environmental degradation resulting from environmental abuse is rapidly and constantly experienced, hence the need for educating the population on the environment. It should be noted however that, the development in the knowledge of Geoinformatics such as Remote Sensing, Geographic Information Systems, Global Positioning Ssystem has help greatly in the understanding of the space technology as well as applying it in every sector of human endavour. In this paper an attempt is made to explain the relevance of GIS and RS to Environmental Education towards Sustainable Nation Development.
\end{abstract}

Keywords: Geographic Information Systems, Remote Sensing, Environmental Education, Sustainable Development, Nigeria.

\section{I NTRODUCTION}

The goal of sustainable planning, policies, and governance is to design processes that return our planet to a more balanced level of use. To do so we must realign our values and earth's ability to support them. The success of this effort is dependent upon a foundation of science and technology knowledge particularly geoinformatics technology, Environmental Education, as a means of collaboration, and the implementation of sustainable polices and administration. Geographic Information System and Remote Sensing as components of geoinformatics technology are essential tools for designing and implementing sustainable processes at a scale ranging from local to global.

The earth environment has provided mankind with the most valuable and greatest asset; he depended on it for his agricultural practices to produce his food and raw materials for his industries. The Rivers, Seas, and Oceans compliments the agricultural produce of man with water resources, the vegetation also provide forest product for man consumption etc.

The importance of science and technology in the development of any nation of the world is no longer a doubt; in fact countries of the world are classified as developed, developing or underdeveloped mainly on the basis of their scientific and technological developments, Itamah (2007).

Further more for any development to be meaningful in any nation there is need for effective knowledge in science and technology particularly space technology which can provide efficient data and information on the environment which will brings effective sustainable development in the world and the Nigeria in particular. 
The National Policy of Education made it clear on the critical issues of science and technology where it stated that, science and technology have been the critical instruments used to uplift the economy of any country but their absorption and application depend very much on the environment Federal Republic of Nigeria (2004).

It should be noted however, all over the world today we depend on the environment for all our needs such as health, food safely and survival, though through our activities consciously or unconsciously we continuously destroying the environment more especially through the advancement in human activities such as industrial, agriculture etc hence the need for environmental education to educate environmental users on the danger of tempering with the environment and without proper maintenance of environment if at all we want have a sustainable national development in Nigeria.

However, in Nigeria today to attain sustainable development there is the need for modern and vibrant environmental education strategy that provides every Nigerian to facilitate and provides the nation with adequate manpower to exploit the natural environmental potential for growth and development. Therefore it advocates for transparency and involvement of the broadest representation of stake holders, groups and socio-political perspectives, Report of the Federal Republic of Nigeria (2004).

In this paper an attempt is made to explain how relevance is geoinformatics technology particularly Geographic Information Systems (GIS) and Remote Sensing (RS) to environmental education and how this can enhance sustainable development in Nigeria.

\section{What is Geographic I nformation Systems (GIS)?}

The use of Geographic Information Systems (GIS) and Geographical Information (GI) plays a key role in human activities today. Geographic Information Systems is widely applied in everyday life by many of the services we rely on. It is one of the fastest growing uses of computer technologies and is a fundamental part of modern geography.

A Geographic Information Systems (GIS) is a computer system for capturing, storing, checking, and displaying data related to positions on Earth's surface. GIS can show many different kinds of data on one map. This enables people to more easily see, analyze, and understand patterns and relationships.

The techniques of Geographic Information Systems can include all stages of data collection, data processing, data base management, data analysis and modelling and data presentation, to end use in the creation of maps and spatial information products, Ikhuoria and Rilwani (2002). They further argued that, Geographic Information Systems (GIS) principles involve data gathering, data processing, database management, data modelling and visualisation in a digital computer environment. Automated data capture systems include multi-spectral remote sensing processes, Global Possioning System (GPS) data, map digitisation and scanning, and computer input and output technologies.

Geographic Information System (GIS) is a technological tool for comprehending geography an d making intelligent decisions. GIS organizes geographic data so that a person reading a map can select data necessary for a specific project or task. However, Geographic Information Systems can combine information from cartographic sources maps in particular, earth bound surveys, remote sensing (aerial and satellite imageries) and create overlapping layers that can be accessed, transformed and manipulated interactively in one spatial structure, Kaminska et al (2004).

Fabiyi (2004) defined Geographic Information Systems as a unique integration of computer hardware, software, peripherals, procedural techniques, organizational structure, people and institution for capturing, manipulating, storing, analyzing, modulating, modeling and displaying geographically referenced data for solving complex human related problems. This definition suggests that Geographic Information Systems is neither the software nor hardware, it neither is 
the procedure to solve problem, but a good integration of all these components of Geographic Information Systems.

A geographic information system (GIS) is a computer system for capturing, storing, checking, and displaying data related to positions on Earth's surface. Geographic Information Systems can show many different kinds of data on one map. This enables people to more easily see, analyze, and understand patterns and relationships.

With Geographic Information Systems technology, people can compare the locations of different things in order to discover how they relate to each other. For example, using Geographic Information Systems the same map could include sites that produce pollution, such as gas stations, and sites that are sensitive to pollution, such as wetlands, such a map would help people determine which wetlands are most at risk.

\section{What is Remote Sensing (RS)?}

Remote Sensing involves the acquisition of spatial data of the environment without physical contact with the objects or features being sensed by using electromagnetic energy radiation, interaction and detection principles in analogue or digital formats.

Cambell (2006:6) described remote sensing as the practice of driving information about the earth's land and water surfaces using images acquired from an overhead perspective, by employing electromagnetic radiation in one or more regions of the electromagnetic spectrum, reflected or emitted from earth's surface.

Similarly, remote sensing is the science and arts of obtaining information about an object, area, or phenomenon through the analysis of that acquired by device that is not in contact with the object area or phenomenon under investigations, Lillesand et al (2004).

It is important to note that before any process of remote sensing to occur there certain elements that comprises the process of remote sensing, thus, energy source or illumination, radiation and the atmosphere, interaction with the target, recording of energy by the sensor, transmission, reception, and processing, interpretation and analysis and finally application. These seven elements comprise the remote sensing process from beginning to end.

\section{The Concept of Environmental Education}

The environment virtually encompasses everything in the world around us. This includes both natural, physical, biotic and abiotic as well as human socio-economic features. Geographers have long claimed interest not only in the unity that exists in the biosphere (ecosystem concept), but also in the intrinsic quality of individual places. Hence, geographers as resource analyst seek to understand the fundamental characteristics of natural resources and the process through which they could be and should be allocated and utilized to meet the needs of today and tomorrow. However it is clear that environmental education it is a process that is designed in order to enhance a critical way of thinking and knowledge which is expected to give a proper approach to the prevention and recovery of environmental damages.

Environmental education refers to organised efforts to teach about how natural environments function and, particularly, how human beings can manage their behaviour and ecosystems in order to live sustainable. The term is often used to imply education within the school system, from primary to post-secondary. However, it is sometimes used more broadly to include all efforts to educate the public and other audiences, including printed materials, websites, media campaigns, etc. Related disciplines include outdoor education and experiential education. Outdoor education means learning in and for the outdoors. It is a means of curriculum extension and enrichment through outdoor experiences. Experiential education is a process through which a learner constructs knowledge, skill, and value from direct experiences. Experiential education can be 
viewed as a process and method to deliver the ideas and skills associated with environmental education, Palmer (1998) cited in Karydas and Manakos (2008).

The Nigerian environment is saddled with many activities in which its quality is being degraded. Such environmental problems like deforestation, flooding, erosion, industrial pollution, oil pollution, rainstorm, bush burning, solid waste management to mention but a few are bedeviling the country Ajibade, (2000). These sets of problems have encouraged underutilization of resources and generated or subjected many of the populace to poverty.

Environmental or conservation education aims; to provide learners with the opportunity to gain an awareness or sensitivity to the environment, knowledge and experience of the problems surrounding the environment, to acquire a set of values and positive attitudes, to obtain the skills required to identify and solve environmental problems and, the motivation and ability to participate Jacobson et al., (2006).

Lawal (2008), defined environmental education as the learning process through which is imparted to its target groups in Schools, Homes, factories, farms, markets, etc, the environmental sensitive awareness, knowledge, attitude, skills, commitments and civic action needed for understanding, protection and improvement of the environment and the prevention or solutions of its allied problems.

In another development, Muibat et al (2008) opined that, environmental education is a problem solving techniques which is concerned with the experience, observation, monitoring and measurement with environmental systems and problems aimed at solving environmental issues the world over, it uses both scientific and humanistic approaches of taking responsibility for the whole system. They further argued that, environmental education is conceived as a platform to explore the entire gamut of education for the purpose of ultimately changing the entire behavior of the society towards the biosphere, this is in order to achieve the objectives of conservations, thus formal environmental education, non-formal environmental education, community based environmental education and special (professional and vocational) environmental education.

The declaration of 2005 to 2014 as the Decade of Education for Sustainable Development heralds a new phase in the continuous evolution of environmental education and its subsidiary, conservation education. This initiative, for which UNESCO is the lead agency, is an international educational effort that aims to encourage changes in behaviour that will create a more sustainable future in terms of environmental integrity, economic viability and a just society for present and future generations UNESCO, (2005).

Approaches to environmental education have evolved dramatically from their natural science base of the 1960s to a social sciences orientated perspective in the 1990s and present day Palmer and Birch, (2005). Originally environmental education was considered to be simply nature studies and it was only in the 1970s that environmental studies and conservation education first emerged. In the 1980s, the promotion of environmentally responsible behaviour became the primary goal of environmental education Mappin and Johnson, (2005), so that the broad title of environmental education now included global education, politics and development studies.

In the last 15 to 20 years this has been expanded to incorporate capacity building and action research aimed at the resolution of socio-economic problems Palmer and Birch, (2005). In effect environmental education has become education for behavioural, personal and social change Mappin and Johnson, (2005).

Education, both formal and informal, is widely used as a conservation intervention in order to develop positive attitudes, and it is often assumed that effective education will automatically lead to environmentally responsible behaviour Dobson, (2007).

Environmental or conservation education aims; to provide learners with the opportunity to gain an awareness or sensitivity to the environment, knowledge and experience of the problems surrounding the environment, to acquire a set of values and positive attitudes, to obtain the skills required to identify and solve environmental problems and, the motivation and ability to participate Jacobson et al., (2006). 
It should be noted that, in Nigeria nowadays there are increase in environmental degradation geometrically with industrialization and agricultural intensification as such it is paramount for the general populace to be awaken and educated by both government and all stake holders in the country on the danger of tempering the naturality of the environment, this will indeed bring about positive changes and thereby prevent any future disasters in our environment.

\section{The Concept of Sustainable Development}

The concept of sustainable development touches upon all aspects of the social and institutional fabric. In this sense sustainable development provides a way of articulating the overall social project and aim of development. Since the Earth Summit in 1992 in Rio de Janeiro, there has been increasing recognition of the critical role of education in promoting sustainable consumption and production patterns in order to change attitudes and behavior of people as individuals, including as producers and consumers, and as citizens.

According to Okebukola (2007), sustainable development means the fulfillment of human needs with protection of natural environment so that these needs can be met not only in the present but in the indefinite future. He further argued that unsustainable situation occur when natural capital (the sum of nature's resources) is used faster than it can be replaced. This result in to environmental degradation the consequences of which would be local environments that is no longer able to sustain human population to any degree, hence extinction of humanity.

Wikipedia (2009), define sustainable development as a pattern of resources use that aims to meet human needs while preserving the environment so that these needs can be met not only in the present but also future generation.

Kaufman and Cleveland (2008) defined sustainable development as the development that meets the needs of the present without compromising the ability of future generations to meet their own needs.

Sustainable development can be seen not so much as a technical concept but as an educational one, not so much the end goal of a government policy but a process of learning how to think in term of forever, Ogunleye (2007).

Sustainable development has been amplified to integrate issues on economic growth, social development and environmental protection during the Rio Earth Summit of 1992 and the Johannesburg summit on sustainable development of 2002. It has generally been accepted that achieving sustainable development will require balancing the environment, social and economic considerations in the pursuit of development for an improved quality of life.

Sustainable development in no small measure does not focus solely on environmental issues but virtually all aspect of human endavour, the World Health Organisation (WHO) (2005) refers to the independent and mutually reinforcing pillars of sustainable development as economic development, social development, environmental protection and the fourth being cultural.

It should be noted that, development refers to changes and is basically used to describe the process of economic and social transformation within nations. In another development Goulet (1977) cited in Thirlwall (2004), opined that, development has three basic components. These are life-sustenance, which is concerned with the provision of basic needs such as housing, clothing, food and minimal education, another components is the self-esteem which is concerned with the feeling of self-respect and independence. However, there is no country that can be regarded as fully developed if it is exploited by others and does not have the power and influence to conduct relations on equal terms and final freedom refers to freedom free from three evils of want, ignorance and squalor so that people are more able to determine their own destiny. Man is not free if he can not choose, if he is imprisoned by living on the margin of subsistence with no education and skills. All the above components of development are interrelated, and interconnected.

It is obvious to note that, sustainability is paradigm for thinking about a future in which environmental, societal and economic considerations are balanced in the pursuit of development 
and improved quality of life. Further more, there are number of ideas and principles underlying sustainability, thus intergenerational equity, gender equity, just and peaceful societies, social tolerance, environmental preservation and restoration, poverty alleviation and natural resources conservation.

\section{Environmental Education and Sustainable Development}

The critical position of environmental education for sustainable development needs no emphasis with declaration of 2005-2014 as the decade for education for sustainable development. As opined by Okebukola (2007), the United Nation (UN) recognizes that there can be few more pressing and critical goals for the future generations, in a way that respects our common heritage the planet we live on.

He further argued that, the link between environment and development was first made in 1980 when the International Union for the Conversion of nature published by the world conservation strategy and used the term sustainable development. He added that, the field of sustainable development can be broken in to four constituent parts, thus: environmental sustainability, economic sustainability, social sustainability and political sustainability. It is therefore clear that, environment, hence environmental education is a key for realization of sustainable development.

It should be noted that, countries of the world have all developed suitable strategies in the direction of environmental education. Nigeria, however developed such strategies in the same direction, for instance in Nigeria there are the establishment of both Federal and State Ministries of environment which indeed is deliberate attempt to give the issue of environment a greater concern in the country's desire to build greater and truly sustainable development.

The awareness among the public and industrial generators has to be created and motivated by the updated techniques and incorporating the innovative and implementable solutions to reform our economy. These can be achieved through environmental education.

It is important to realise that, environmental education has two fundamental components these components help tremendously toward successful environmental knowledge; these components include alerting the public to the need to achieve global sustainable development and the likely consequences of failing to do so and secondly focusing the educational curricula for global sustainable development by incorporating the know-how and skills and also the moral imperatives.

Environmental education is a process that is designed in order to improve a critical way of thinking and knowledge which is expected to give a proper advance to the prevention and recovery of environmental damages. Dasgupta (2007), stated what necessitate the need for environmental education in a society that required sustainable development like Nigeria. He further explained that, a society cannot survive if its natural resources are rendered unfit for use by its people; therefore most of the major natural resources in the country are in grave danger of irreparable damage and the only hope of salvaging this grave situation is by making the young aware that they need to practically begin to protect the environment they inherit.

Secondly, is the moral and ethical education for changing people's attitude to protect children living in polluted regions is only through environmental education which represents a relevant means of prevention.

\section{Relevance of Geographic I nformation System and Remote Sensing to Environmental Education for Sustainable Development}

Koinyan (1999) in Ifemuyiwa (2007) says that, development starts only when man is able to take total control of his environment to manipulate and manage progressively every thing in that environment and to increase the production of all those things he needs to live a qualitatively 
better life, thus development is the ultimate desire of individuals, nations and any human endavour.

Geographic Information System (GIS) and Remote Sensing (RS) software has proven to be a useful tool in both formal and non-formal environmental education programs. Although still not widely used in schools compared with other educational technologies.

Geographic Information System (GIS) and Remote Sensing (RS) has been shown to be a beneficial tool which can be used to analyze and integrate a variety of data pertaining to environmental issues. This is an attractive feature in a field characterized by a trend toward the use multi-disciplinary methods in the study of environmental issues which will enhance knowledge for populace in the improvement of their environment as well encourage sustainability in Nigerian environment.

As Geographic Information System (GIS) and Remote Sensing (RS) software, hardware, and training continue to become more accessible to schools, teachers, students, and general public can expect to see a continued increase in the use of Geographic Information System (GIS) and Remote Sensing (RS) for environmental education in Nigeria.

With Geoinformatics technology, Geographic Information System (GIS) and Remote Sensing (RS) in particular people can compare the locations of different things in order to discover how they relate to each other. For example, using Geographic Information System (GIS), the same map could include sites that produce pollution, such as gas stations, and sites that are sensitive to pollution, such as wetlands, such a map would help people determine which wetlands are most at risk.

There is no doubt that one of the most important prerequisites for sustainable development is the availability of accurate, reliable, up-to-date and standard geoinformatics data particularly that of Geographic Information System and Remote Sensing on natural and cultural resources of the country. Such data and information is required at various levels for different purposes, for example, a tourist who needs to know the location and direction of a tourist spot; demographers need information on the total number, distribution and composition of the population; industrialists need to know the best location to establish an industry; agriculturalists, foresters, soil scientists, environmentalists, policy makers and planners all need data and other vital information to chalk out the development activities and conservation strategies to achieve sustainable development.

Geographic Information System and Remote Sensing play several different yet complementary roles in relation to sustainable development and environmental education that will enhance sustainable development in Nigeria.

Geographic Information System provides a means of converting spatial data into digital form that can then be stored, retrieved, displayed, manipulated, modified, analysed, and reproduced quickly in a new format, available for either visual display or hard copy reproduction that to educate individuals on managing their environment for future destruction.

Geographic Information System can be used for constructing models for analyzing trends and identifying factors that affect them and to simulate the effect of a specific process over time for a given scenario. Such models can also be used for environmental impact assessment or for displaying the possible consequences of planning decisions or projects that affect resource use and management.

Forestry planners can use Geographic Information System and Remote Sensing to monitor the impacts of deforestation and the wildlife manager can use technology to determine the size and location of animal populations or to determine areas having high food and habitat potential for specific species and this provide information on the issue of food security.

Geographic Information System and Remote Sensing technology can also be used as a potential media tool for creating awareness related to the country's natural and human resources and biodiversity conservation through environmental education.

Geographic Information System and Remote Sensing as new and upcoming technology in Nigeria can provides a platform for individuals and organisations to share and upgrade data and 
information and facilitate real time and instant communication network on the matters of environmental management for future uses.

It is important to note that, Geographic Information System and Remote Sensing technologies help to provide information and knowledge to policy makers and environmentalist on areas with severe environmental pressure which will provide efficient knowledge on how to manage the environment.

With development of geoinformatics technology in Nigeria it can serve as a tool for spatial data collation, processing, storage, indexing, retrieval, analysis and communication of spatial information, its use in the country for natural and water resources and environmental research, monitoring, analysis and management has a positive role to play in the effective monitoring, control and management of theses resources towards finding solutions to the modern day environmental problems and natural resources management.

\section{Conclusion}

The field of Geographic Information System and Remote Sensing had a critical role to play in the use of geospatial data and information in national developmental issues, resource management, environmental monitoring and control, regional integration and international cooperation.

With the field of Geographic Information System and Remote Sensing critical to the development of various sectors of the economy including petroleum, solid minerals, forestry, agriculture, transport and aviation, environment, security, defense, tourism, population census, monitoring and control education, health and water resources management, its use as a decision making tool in the decision making process is of paramount importance which had been recognized by the government in Nigeria and other Africa nations.

However, while the integration of the Geoinformatics technology particularly in Geographic Information System and Remote Sensing is in the development stage in the country, positive steps had been taken by government and other stakeholders involved in the development and promotion of Geoinformatics use for research, training and production of empirical data for policy formulation at the local, regional and national level towards environmental monitoring and management, resource management and developmental planning.

However, there are expectations that having professional Geographic Information System and Remote Sensing consultants and experts will go a long way in developing the field of environmental education in the country for meeting future task and demand and solving modern day environmental and natural resources management problems.

\section{Recommendations}

There is the need to protect children living in polluted regions; environmental education represents a relevant means of prevention because this type of education encourages learner's awareness of their environment's ambient conditions, as well as their active participation in solving local problems. It is the need of the hour to propose environmental education with the essential elements of moral philosophy.

Conventional educational methods are no longer adequate for the real needs of tomorrow. Future engineers and also other students of specialised areas must acquire knowledge and skills in their own field and keep pace with rapid advances in practically all branches of engineering as well as the other areas of specialisation..

The communication perspective opens the door to other kinds of tools that environmental educators can use in order to improve the educational practice.

To this end a generic outline syllabus, including essential elements of moral philosophy has to be proposed for environmental education in schools and also undergraduate students in college level. 
There are also challenges to be met in the area of Database development in the country with the implementation of institutional framework guidelines already set in place for the full integration of the Geoinformatics technology at every facet and levels of government and organisation in the country for better decision making and policy formulation and development.

\section{References}

Ajibade, L.T. (2000). Techniques of creating Environmental Awareness in Nigeria. In Jimoh, H.I. and I fabiyi, I.P.(eds) Contemporary issues in Environmental Studies. Haytee Press \& Publishing. Pp 277-286.

Cambell, J.B. (2006). Introduction to Remote Sensing. London Taylor and Francis Dasgupta, (2007). The idea of sustainable development, Sustainability Science 2(1): 5-11

Dobson, A. (2007). Environmental citizenship: towards sustainable development. Sustainable Development, 15, 276-285.

Fabiyi, S. (2004). "Application of Geographic Information Systems (GIS) and Land Information Systems (LIS) in Urban and Regional Planning". 2004 MCPDP. NITP and TOPREC: Ada, Osun State, Nigeria. Federal Republic of Nigeria (2004). National Policy on Education, Lagos NERDC Press.

Ifemuyiwa, A.S. (2007). Mathematics Education for sustainable development. proceedings of the Annual National Conference of Science Teachers Association of Nigeria (STAN) PP.162-165

Ikuoria I.A and Rilwani, M.L 2002. The Concept of Precision Agriculture with Geoinformatics for Sustainable Development. In: E Gideon, GE Omuta, Isi A Ikhuoria (Eds.): Geography and Sustainable Development in Nigeria: Philosophical and Conceptual Issues, Benin City, Nigeria: Nigeria Geographical Association, pp. 89-104.

Itamah, D.A. (2007), Functional Science, Technology and Mathematics (STM) Education for National Economic Development. Nigerian Journal of Science and Education Research, 2007 1, 1-8

Jacobson, S., McDuff, M. \& Monroe, M. (2006). Conservation Education and Outreach Techniques. Oxford Biology, Oxford, UK.

Kaufman, R. K. and Clevend C. J. (2008). Environmental Science. New York McGraw Hill. P. 194.

Karydas, C.G.and Manakos.I. (2008). Contribution of Geo-Informatics to Environmental Education: a worked example from the research', 2nd WSEAS/IASME International Conference on Energy Planning, Energy Saving, Environmental Education Proceedings: pp 135-141

Kaminska, I.A, Oldak, A, and Turski, W.A. (2004). Geographic Information Systems (GIS) as a toolfor monitoring and analyzing pesticide pollution and its impact on public health, Annals of agriculture and environmental medicine. Vol.II (2): 181-184.

Lawal, M.K.. (2008). Environmental Education in Okoro, R.U (2008): The teacher and effective teaching. Revised edition: King treasure publishing house.

Lillesand TM, Kiefer, RW and Chipman, JW (2004). Remote Sensing and image interpretation, $5^{\text {th }}$ edition. J ohn Wile and sons, New York, 35-445.

Mappin, M. and Johnson, E. (2005). Changing perspectives of ecology and education in environmental education. In E. Johnson and M. Mappin, eds., Environmental Education and Adovocacy: Changing Perspectives of Ecology and Education, Cambridge University Press, Cambridge.

Muibat, O, Muhammad A.U and Luba M.J . (2008). Environmental Education and its relevance to Nigerian vision 20:2020: A paper presented at the 2008 National Conference of Shehu Shagari College of Education, Sokoto.

Ogunleye, O.A (2007). Building a sustainable science curriculum in Nigeria: Accommodating local adaptation, leverging technology and enhancing areas of improvement for quality assurance. Proceedings of the $5^{\text {th }}$ Anniversary Conference of STAN, held at Sokoto.

Okebukola, P.O.A (2007). Science, Technology and Mathematics Education for sustainable development, key note address at the golden jubilee anniversary conference of Science Teachers Association of Nigeria (STAN) held at Sokoto.

Palmer, J. and Birch, J. (2005). Changing academic perspectives in environmental education research and practice: progress and promise. In E. Johnson and M. Mappin, eds., Environmental Education 
and Adovocacy: Changing Perspectives of Ecology and Education, Cambridge University Press, Cambridge, UK.

Thiriwall, A.P. (2004). Growth and development with special reference to developing economies. India, Palgrav, Macmillan

UNESCO (2005). http://portal.unesco.org/education/en/ev.php URL_ID=23279\&URL_DO=DO_TOPIC\&UR L_SECTION=201.html [Accessed 24th November 2005].

World Health Organistaion (WHO) (2005). World Summit Outcome Documents.

http://en.wikipe.org/wiki/sustainable_dvelopment. Retrieved on 17/06/2013 